\title{
Solid-phase Refolding of Poly-lysine Tagged Fusion Protein of hEGF and Angiogenin
}

\section{Sang Joong Park ${ }^{1}$, Kang Ryu ${ }^{1}$, Chang Woo Suh ${ }^{1}$, Young Gyu Chai ${ }^{2}$, Oh Byung Kwon ${ }^{3}$, Seung Kook Park ${ }^{3}$, and Eun Kyu Lee ${ }^{1 *}$}

${ }^{1}$ Department of Chemical Engineering, ${ }^{2}$ Department of Biochemistry and Molecular Biology, Hanyang University, Ansan 425-791, Korea

${ }^{3}$ Central R\&D Center, DaeWoong Pharmaceutical Co., Ltd., YongIn, Korea

\begin{abstract}
A fusion protein, consisting of a human epidermal growth factor (hEGF) as the recognition domain and human angiogenin as the toxin domain, can be used as a targeted therapeutic against breast cancer cells among others. The fusion protein was expressed as inclusion body in recombinant $E$. coli, and when the conventional, solution-phase refolding process was used the refolding yield was very low due to severe aggregation. It was probably because of the opposite electric charge at a neutral $\mathrm{pH}$ resulting from the vastly different $\mathrm{pI}$ values of each domain. The solidphase refolding process that exploited the ionic interactions between ionic exchanger surface and the fusion protein was tried, but the adsorption yield was also very low, below $30 \%$, regardless of the resins and $\mathrm{pH}$ conditions used. Therefore, to provide a higher ionic affinity toward the solid matrix, six lysine residues were tagged to the $N$-terminus of the hEGF domain. When heparinSepharose was used as the matrix, the adsorption capacity increased 2.5-3 times to about 88\%. Besides the intrinsic affinity of angiogenin to heparin, the poly-lysine tag provided additional ionic affinity. And the subsequent refolding yield increased nearly 13 -fold, from ca. $4.8 \%$ in the conventional refolding of the untagged fusion protein to $63.6 \%$. The process was highly reproducible. The refolded protein in the column eluate retained RNase bioactivity of angiogenin.
\end{abstract}

Keywords: refolding, solid-phase refolding, inclusion body, fusion protein, cationic tagging, heparin

\section{INTRODUCTION}

The targeted delivery of cytotoxins to specific cellular receptors using a fusion protein technique has been recently used as a highly selective and effective approach in cancer treatment $[1,2]$. In one case, a human EGF (epidermal growth factor; pI 4.5, $6 \mathrm{kDa}$ ) has been used as the recognition domain [3] and a human angiogenin (pI 9.0, $14 \mathrm{kDa})$ as the toxin domain $[4,5]$. Here the Cterminus of the EGF is linked to the $N$-terminus of the angiogenin by a linker peptide consisting of five amino acids (GGGGS) [2]. The EGF acts as a targeting marker for EGF receptors that are expressed on the surface of certain tumor cells. Then, after the fusion protein is internalized, the angiogenin acts as a ribonucleolytic toxin killing the tumor cells $[4,5]$.

In this study, to investigate the potential for mass production, this fusion protein (E5A) was expressed as inclusion body in E. coli, and several traditional refolding processes applied. When the conventional, solutionphase refolding process consisting of rapid dilution followed by dialysis was used, the refolding yield was very low (ca. $4.8 \%)$ due to severe aggregation. This was pro-

* Corresponding author

Tel: +82-31-400-5275 Fax: +82-31-408-3779

e-mail:eklee@hanyang.ac.kr bably because of the opposite electric charge of the two domains at the refolding $\mathrm{pH}$ (i.e., 7.0) that resulted from the vastly different pI values of each domain (4.5 for EGF and > 9.0 for angiogenin).

Therefore, to circumvent the aggregation problem, a solid-phase refolding method was introduced. Basically, solid-phase refolding consists of three sequential steps: adsorption of the solubilized proteins to the surface of a solid matrix, refolding on the surface of the solid matrix by washing off the denaturant, and elution from the solid surface. This solid-phase refolding process has several potential advantages. First, it can minimize the aggregation because protein-protein interactions can be systematically avoided. Second, a relatively higher protein concentration can be maintained during refolding, which depends on the adsorption capacity of the protein relative to the given matrix. In addition, the solidphase refolding process can decrease the overall refolding process time and bypass the extra post-refolding step of separating the monomers from the aggregate [68].

Six lysine residues followed by a tetrapeptide of the factor Xa cleavage sequence were tagged to the $N$ terminus of E5A (6L10E5A) to increase it's binding capacity to a cationic exchanger and provide an enzymatic cleavage site, respectively. Accordingly, this paper presents the detailed procedure involved in applying the 
solid-phase refolding concept to 6L10E5A refolding, and compares the performance of the new solid-phase refolding process with that of the conventional solutionphase refolding focusing on the refolding yield.

\section{MATERIALS AND METHODS}

\section{Fusion Protein Expression}

Human angiogenin DNA was cloned into the pRSET expression vector (Invitrogen), pRAng. Human EGF cDNA containing plasmid pTE105, pTED was used. The construction of plasmids pTEA was designed to express the fusion protein EGF-(gly) ${ }^{4}$ ser-angiogenin (E5A) in E. coli. The details of the plasmid construction is described elsewhere [2,9], and this work was performed by DaeWoong Pharmaceutical Co., Ltd. The same vector system was used for 6L10E5A expression. For the recombinant E. coli fermentation, a GNPF medium was used, then to express the fusion proteins (E5A or 6L10E5A) $1 \mathrm{mM}$ IPTG was added during the mid-exponential phase. The molecular weight of E5A and $6 \mathrm{~L} 10 \mathrm{E} 5 \mathrm{~A}$ was ca. $21 \mathrm{kDa}$ and $22 \mathrm{kDa}$, respectively. The detailed fermentation and expression procedure is described elsewhere [10].

\section{Inclusion Body Isolation and Solubilization}

After the fermentation, the cells were harvested by centrifugation $(12,000 \mathrm{rpm}, 20 \mathrm{~min})$. SDS-PAGE (16\%) and Western blotting were used to check the expression of the target protein, and the expression level was quantified by using a scanning densitometer. The isolated cells were added to a lysis buffer $(100 \mathrm{mM}$ sodium phosphate, 1\% Tween 20, pH 7.0) and disrupted by sonication. The cell disrupt was centrifuged at 8000 rpm for 30 min to recover the inclusion body (IB) pellets, which were then washed three times using a wash buffer $(50 \mathrm{mM}$ sodium phosphate, 1\% Tween 20, pH 7.0). The washed IB was finally dissolved in a solubilization buffer ( $8 \mathrm{M}$ urea, $50 \mathrm{mM}$ sodium phosphate, $\mathrm{pH}$ 7.0).

\section{Solid-phase Refolding}

To identify a suitable solid matrix and appropriate binding conditions, the equilibrium adsorption capacity of the two solubilized proteins, E5A and 6L10E5A, was determined at different $\mathrm{pHs}$ and ionic strengths using various resins. CM-Sepharose, Q-Sepharose, DEAESepharose, heparin-Sepharose, and phenyl-Sepharose were all purchased from Amersham Pharmacia Biotech, Uppsala, Sweden. To the solubilized IB solution of 1 $\mathrm{mg} / \mathrm{mL}$ total protein concentration, $0.5 \mathrm{~mL}$ of each resin was added. After mixing and sedimentation, the protein concentration in the supernatant was analyzed by the Bradford assay to calculate the adsorption capacity.

After identifying the suitable resin and conditions,

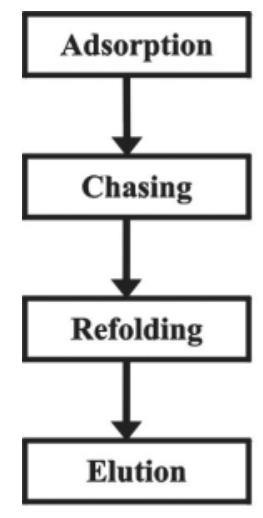

Loading of $10 \mathrm{mg}$ of total proteins

Buffer: $8 \mathrm{M}$ urea, $50 \mathrm{mM}$ sodium phosphate, $\mathrm{pH} 7$

Removal of non-specifically bound proteins

Buffer: $8 \mathrm{M}$ urea, $50 \mathrm{mM}$ sodium phosphate, $\mathrm{pH} 7$

3 Bed volume; flow rate $=0.4$ bed volume $/ \mathrm{min}$

Washing out urea

Buffer: $\mathbf{5 0}$ mM sodium phosphate, pH 7

$3 \mathrm{Bed}$ volume; flow rate $=0.4$ bed volume $/ \mathrm{min}$

Salt gradient elution of the refolded protein

Buffer: $50 \mathrm{mM}$ sodium phosphate, $2.0 \mathrm{M} \mathrm{NaCl}, \mathrm{pH} 7$

3 Bed volume; flow rate $=0.4$ bed volume $/ \mathrm{min}$

Fig. 1. Flow chart of solid-phase refolding.

we performed the solid-phase refolding experiments in a packed column ( $5 \mathrm{~mL}$ bed volume). After the adsorption of 6L10E5A to the resin, the urea was removed by washing the column with a urea-wash buffer $(50 \mathrm{mM}$ sodium phosphate, $\mathrm{pH}$ 7.0). During this step the adsorbed fusion protein was solid-phase refolded as attached to the resin surface. The refolded protein was eluted by applying a linear gradient of the elution buffer (50 mM sodium phosphate containing $2 \mathrm{M} \mathrm{NaCl}, \mathrm{pH}$ 7.0) from 0 to $2 \mathrm{M} \mathrm{NaCl}$ for $25 \mathrm{~min}$. Fig. 1 shows the flowchart of the solid-phase refolding procedure and conditions.

The RNase bioactivity of the refolded 6L10E5A in the eluate was measured by a tRNA assay [4]. Refolding yield was calculated by dividing the mass of 6L10E5A in the column eluate by that in the solubilized IB.

\section{RESULTS AND DISCUSSION}

\section{Expression of E5A and 6L10E5A}

From the fermentation for E5A expression, a final optical density (at $600 \mathrm{~nm}$ ) of 20 and $6.7 \mathrm{~g} / \mathrm{L}$ of DCW (dry cell weight) were obtained. The expression level was about $25 \%$ of the total proteins detected on the gel. The result of the fermentation for $6 \mathrm{~L} 10 \mathrm{E} 5 \mathrm{~A}$ was; final OD of 25 and DCW of $4.7 \mathrm{~g} / \mathrm{L}$. The expression level was approximately $21 \%$ of the total proteins. The expression profile of 6L10E5A during the fermentation was checked by Western blots for the anti-hEGF antibody and anti-angiogenin antibody, and the results are shown in Fig. 2. It was observed that some of the 6L10E5A was constitutively formed before the IPTG induction, yet the majority of the protein was expressed after the induction.

\section{Adsorption Capacity of E5A}

When the solubilized protein was refolded using the conventional method (rapid dilution followed by dialysis), severe aggregation was observed with a very low recovery yield [11]. Also a long refolding time, about 24 


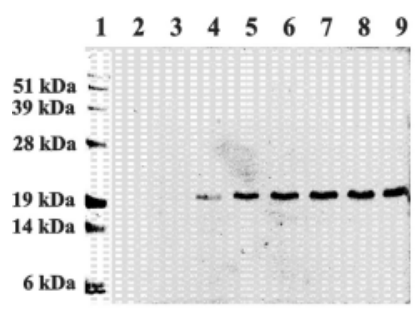

Anti-EGF

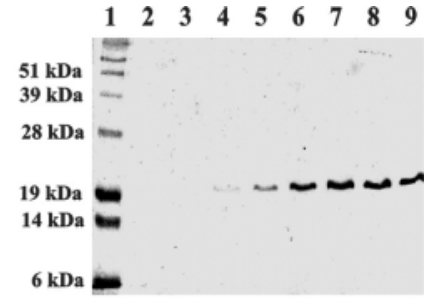

Anti-angiogenin
Fig. 2. Western blotting result of 6L10E5A fermentation. Lane 1: MW marker, Lane 2: $5 \mathrm{~h}$ before induction, Lane 3: $3.7 \mathrm{~h}$ before induction, Lane $4: 2.5 \mathrm{~h}$ before induction, Lane $5: 1 \mathrm{~h}$ before induction, Lane 6: induction point, Lane 7: $1 \mathrm{~h}$ after induction, Lane 8: $2 \mathrm{~h}$ after induction, Lane 9: $4 \mathrm{~h}$ after induction.

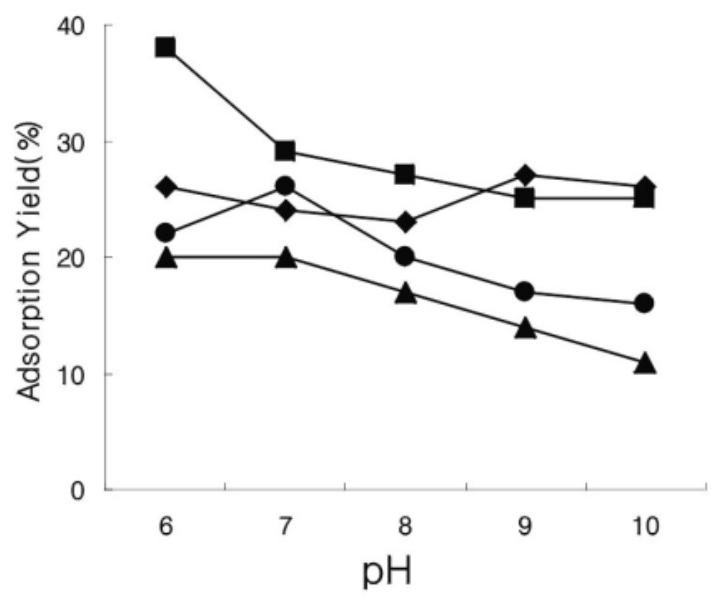

Fig. 3. Adsorption yield of E5A with different resins and various pH. Q-Sepharose ( ), CM-Sepharose (•), DEAESepharose $(\mathbf{\Delta})$, heparin-Sepharose $(\boldsymbol{\square})$.

h, was necessary. When applying the solid-phase refolding, the key was to identify the appropriate adsorption matrix and conditions. Four types of ion exchangers (CM-Sepharose, heparin-Sepharose, Q-Sepharose and DEAE-Sepharose) were tested at various pH $(6,7,8,9$, 10). Although the binding yield varied in each case, the adsorption capacity remained below $30 \%$ (0.3 mg$\mathrm{E} 5 \mathrm{~A} / \mathrm{mL}-\mathrm{resin}$ ) in all the cases (Fig. 3). Also, the adsorption capacity was not affected by the ionic strength (50, 100, 200, 300, and $400 \mathrm{mM}$ were tested). Considering that the fusion protein contained both positive and negative electric charges, we tested the mixed resins of equal volumes of CM-Sepharose and DEAE-Sepharose at $\mathrm{pH}$ 7.0. However, the binding yield was still below $40 \%$ (data not shown). A hydrophobic interaction resin (phenyl-Sepharose) was also tested, yet the binding yield remained very low.

Heparin is known to have affinity to angiogenin [12]. When we tried heparin-Sepharose as the matrix the binding yield was higher than others, but the highest yield was $38 \%$ at pH 6.0 (see Fig. 3). It was still low to

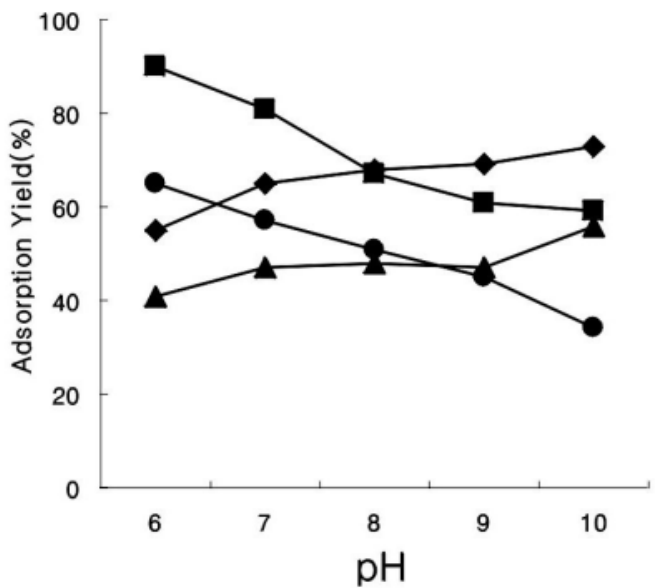

Fig. 4. Adsorption yield of 6L10E5A with different resins and various $\mathrm{pH}$. Q-Sepharose $(\bullet), \mathrm{CM}$-Sepharose $(\bullet)$, DEAESepharose $(\mathbf{A})$, heparin-Sepharose $(\boldsymbol{\square})$.

apply it to the solid-phase refolding, and accordingly, the solid-phase refolding technique was deemed unfeasible due to the very poor affinity of E5A to any kind of resin. This was mainly because the EGF and angiogenin had the opposite electric surface charges, thereby hindering efficient ionic interactions by presenting both attractive and repulsive forces simultaneously.

\section{Adsorption Capacity of 6L10E5A}

Six lysine residues were tagged to the $N$-terminus of E5A (6L10E5A) to provide stronger affinity to a cationic exchanger. Cationic exchange resin was chosen over anionic exchanger because angiogenin (ca. $14 \mathrm{kDa}$ ) is a much larger domain than EGF $(6 \mathrm{kDa})$ and thus represents major electric force of the fusion protein. The solubilized 6L10E5A IB was applied to several resins (CM-, Q-, DEAE-, and heparin-Sepharose) at various $\mathrm{pH}$ $(6,7,8,9,10)$. Fig. 4 indicates that the adsorption yield was significantly improved by the poly-lysine tagging, since it provided stronger affinity to the cationic exchanger. For example, with CM-Sepharose at $\mathrm{pH} 6$, the binding yield was approx. $65 \%$, which was $2.5-3$ times improvement over the E5A case (ca. 21\%).

Heparin-Sepharose exhibited the highest adsorption capacity; approximately $88 \%$ binding yield at $\mathrm{pH} 6$. Considering the fact that without the poly-lysine tagging the binding yield was only about $38 \%$, we could conclude the enhanced adsorption to heparin was due to the increase ionic interaction coming from the tag. In other words, the cationic poly-lysine tag further strengthened the intrinsic affinity of cationic angiogenin at $\mathrm{pH} 6.0$ toward heparin. Based on this observation, we selected heparin-Sepharose as the matrix of choice for solid-phase refolding.

Polymers of cationic residues such as histidine, arginine, and lysine are known to present strong affinity toward certain metal-chelating resins such as Ni-NTA (nickel-nitrilotriacetate)-agarose. It was used to purify 

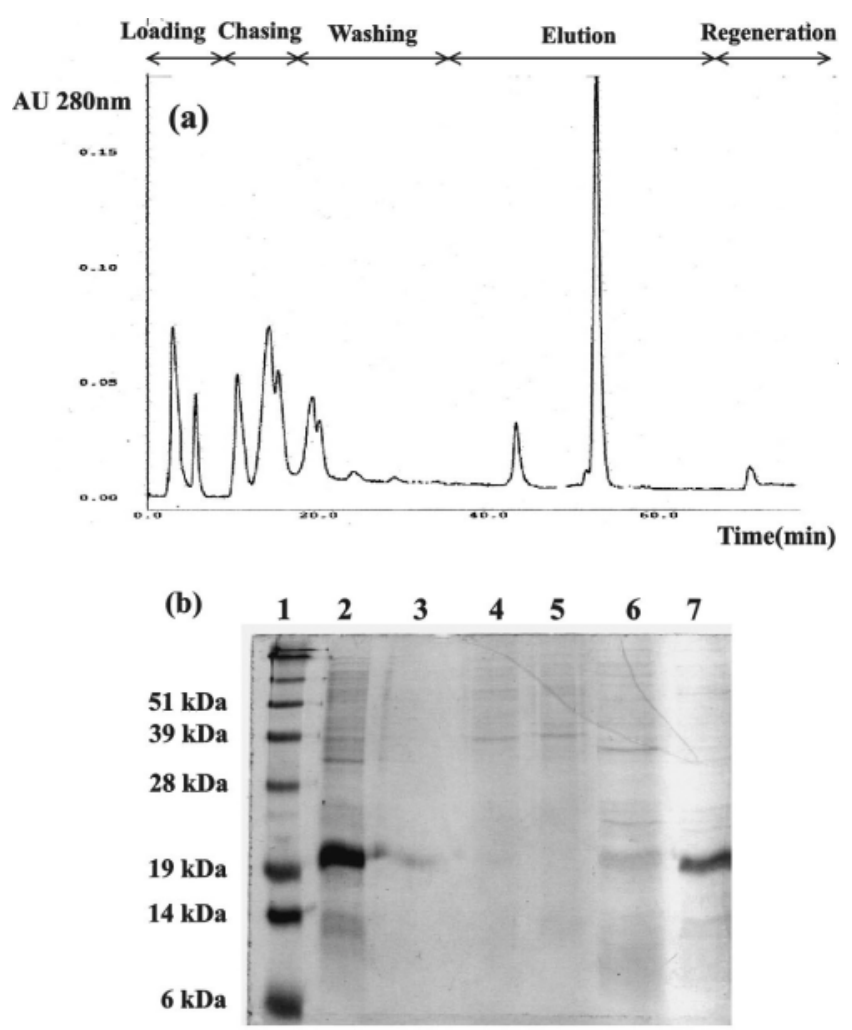

Fig. 5. Solid-phase refolding results in heparin-Sepharose column. (a) heparin-Sepharose chromatogram, (b) SDS-PAGE of heparin-Sepharose chromatogram (Lane 1: MW marker, Lane 2: solubilized IB, Lane 3: $3 \mathrm{~min}$, Lane 4: $10 \mathrm{~min}$, Lane 5: 13 min, Lane 6: $14.5 \mathrm{~min}$, Lane 7: $52 \mathrm{~min}$ ).

recombinant hEGF via the affinity interaction [13]. The same experimental protocol was also applied to 6L10E5A adsorption to Ni-NTA resin for comparison. Between $\mathrm{pH} 7$ and 9, the adsorption yield was rather constant at $70 \pm 5 \%$ (data not shown). Further experiment was not pursued, however, because of cost consideration (it is about $20 \%$ more expensive than heparin-Sepharose) and potential problem associated with imidazole.

\section{Solid-phase Refolding}

The washed IB of 6L10E5A was dissolved in the solubilization buffer containing $8 \mathrm{M}$ urea, and the aliquot containing $10 \mathrm{mg}$ of total proteins was loaded at $2 \mathrm{~mL} / \mathrm{min}$ on the heparin-Sepharose column $(5 \mathrm{~mL}$ bed volume) that was previously equilibrated with $8 \mathrm{M}$ urea. After chasing out any unbound proteins by washing the column with $15 \mathrm{~mL}$ of the solubilization buffer, the urea was washed out by $15 \mathrm{~mL}$ of the urea-wash buffer. During this step, the tagged fusion protein was refolded in the column as with the other fusion protein [14]. After the solid-phase refolding, the fusion protein was eluted by approx. $1.0 \mathrm{M} \mathrm{NaCl}$ or at $52 \mathrm{~min}$ (see Fig. $5(\mathrm{a})$ ). The lane 7 of Fig. 5(b) shows that this peak contained the 6L10E5A. The minor peak eluted at $44 \mathrm{~min}$
Table 1. Refolding yield profiles of fusion proteins

\begin{tabular}{|c|c|c|c|}
\hline & $\begin{array}{l}\text { Conventional } \\
\text { method }\end{array}$ & \multicolumn{2}{|c|}{ Solid-phase refolding } \\
\hline Method & $\begin{array}{l}\text { Dilution / dialysis } \\
\text { / CM-Sepharose } \\
\text { chromatography }\end{array}$ & CM-Sepharose & $\begin{array}{l}\text { Heparin- } \\
\text { Sepharose }\end{array}$ \\
\hline Fusion protein & E5A & E5A 6L10E5A & 6L10E5A \\
\hline $\begin{array}{l}\text { Solubilized } \\
\text { IB mass }\end{array}$ & $1 \mathrm{~g}$ & $1 \mathrm{~g}$ & $1 \mathrm{~g}$ \\
\hline $\begin{array}{l}\text { Recovered } \\
\text { fusion protein } \\
\text { mass }\end{array}$ & $0.048 \mathrm{~g}$ & $0.136 \mathrm{~g} \quad 0.337 \mathrm{~g}$ & $0.636 \mathrm{~g}$ \\
\hline Refolding yield & $4.8 \%$ & $13.6 \%$ & $63.6 \%$ \\
\hline
\end{tabular}

or by approx. $0.2 \mathrm{M} \mathrm{NaCl}$ contained the impurity proteins associated with $E$. coli because they are known to be eluted at this salt gradient [11].

The average refolding yield of the 16 separate experiments was $63.6 \%$ (with the standard deviation of $3.2 \%$ ), which was about 13 -fold improvement over the conventional, solution-phase method of E5A (see Table 1). This improvement is primarily due to the reduced aggregation, because the solid-phase refolding can systematically avoid intermolecular interactions. The data in the first and the second column of Table 1, i.e., the conventional method and the solid-phase method (using CM-Sepharose) of E5A, evidences the benefit of the solid-phase method. The protein concentration was $2 \mathrm{mg}$ of total protein per $\mathrm{mL}$ of resin, which was much higher than the usual concentration used in solutionphase refolding. The higher yield and lower processing volume are the major advantages of the solid-phase refolding. Furthermore, the refolding process time of the conventional method was about $30 \mathrm{~h}$ whereas the solidphase refolding took only $4-5 \mathrm{~h}$, since it is basically a column process with limited feed volumes of each step.

The peak fractionated from the heparin-Sepharose eluate was dialyzed and checked for the RNase activity. Its activity was approx. $65 \%$ of that of the monomeric angiogenin purified from other source. This value of bioactivity indicates that the solid-phase refolded 6L10E5A retains its biological activity. It was also demonstrated by Western blots of hEGF and angiogenin antibodies.

\section{CONCLUSION}

When the solid-phase refolding of the poly-lysine tagged fusion protein of hEGF and angiogenin (6L10E5A) was performed in a heparin-Sepharose column, the refolding yield increased approximately 13-fold, compared with the conventional, solution-phase refolding of the untagged protein (E5A). In addition to angiogenin, the poly-lysine tag provided additional affinity toward 
heparin, thereby resulting in 2.5-3 times improvement in the binding yield. The refolding yield was highly reproducible also because of the solid-phase reaction. The refolding process time was reduced approx. 8-fold. The solid-phase refolded protein retained its intended biological activities. Accordingly, this study demonstrates that the solid-phase refolding method could significantly enhance the refolding yield by suppressing the intermolecular interactions that may result in run-away aggregation.

Acknowlegements This work was supported by the Korea Ministry of Commerce, Industry and Energy. A part of this work was also supported by the Center for Advanced Bioseparation Technology at Inha University.

\section{REFERENCES}

[1] Psarras, K., M. Ueda, T. Yamamura, S. Ozawa, M. Kitajima, S. Aiso, S. Komatsu, and M. Seno (1998) Human pancreatic RNase1-human epidermal growth factor fusion: An entirely human 'immunotoxin analog' with cytotoxic properties against squamous cell carcinomas. Protein Eng. 11: 1285-1292.

[2] Yoon, J. M., S. H. Han, O. B. Kown, S. H. Kim, M. H. Park, and B. K. Kim (1999) Cloning and cytotoxicity of fusion proteins of EGF and angiogenin. Life Science 16: 14351445.

[3] Hirata, Y. and A. N. Orth (1979) Epidermal growth factor (urogastrone) in human fluids: size heterogeneity. J. Clin. Endocrinol. Metab. 48: 673-679.

[4] Shapiro, R., J. F. Riordan, and B. L. Vallee (1986) Characteristic ribonucleolytic activity of human angiogenin. Biochemistry 25: 3527-3532.
[5] Wu, Y. N., S. K. Saxena, W. Ardelt, M. Gadina, S. Mikulski, C. D. Lorenzo, G. D'Alessio, and J. Youle (1995) A study of the intracellular routing of cytotoxic ribonucleases. J. Biol. Chem. 1270: 17476-17481.

[6] Creighton, T. E. (1989) Process for the production of a protein. US Patent 4,977,248.

[7] Sinha, N. K. and A. Light (1975) Refolding of reduced, denatured trypsinogen and trypsin immobilized on agarose beads. J. Biol. Chem. 250: 8624-8629.

[8] Stempfer, G., B. H. Neugebauer, and R. Rudolph (1996) Improved refolding of immobilized fusion protein. $\mathrm{Na}$ ture Biotechnol. 14: 329-334.

[9] Lee, K. M., Y. W. Koh, J. Y. Chung, S. K. Park, and M. W. Park (1997) A novel gene coding human epidermal growth factor and preparing the same. US Patent $8,360,841$.

[10] Lee, Y. S. (1999) Fermentation and Purification Processes for Fusion Protein of Human Epidermal Growth Factor and Angiogenin from Recombinant E. coli. MS Thesis. Hanyang University, Korea.

[11] Kim, C. S. and E. K. Lee (2000) Effects of operating parameters in in vitro renaturation of a fusion protein of human growth hormone and glutathione $S$ transferase from inclusion body. Process. Biochem. 36: 111-117.

[12] Soncin, F, D. J. Strydom, and R. Shapiro (1997) Interaction of heparin with human angiogenin. J. Biol. Chem. 272: 9818-9824.

[13] Lee, J. Y., C. S. Yoon, I. Y. Chung, Y. S. Lee, and E. K. Lee (2000) Scale-up process for expression and renaturation of recombinant human epidermal growth factor from $E s-$ cherichia coli inclusion bodies. Biotechnol. Appl. Biochem. 31: 245-248.

[14] Cho, T. H., S. J. Ahn, and E. K. Lee (in press) Refolding of protein inclusion bodies directly from $E$. coli homogenate using expanded bed adsorption chromatography. Bioseparation.

[Received September 14, 2001; accepted January 15, 2002] 